\title{
A OFERTA DE CURSOS DO PROUNI E O MERCADO DE TRABALHO
}

\author{
COURSES OFFERED BY PROUNI AND THE JOB MARKET
}

\author{
João Marcelo da Costa e Silva Lima* \\ Carlos Ragazzo** \\ Leandro Molhano ${ }^{* * *}$
}

\begin{abstract}
RESUMO
Neste texto, analisamos a atual distribuição de bolsas do Prouni por curso de graduação, para identificar quais as principais áreas de conhecimento que são contempladas no mercado educacional superior por esse programa e em que medida ele se compatibiliza com a necessidade de incentivar a formação superior em áreas de conhecimento consideradas estratégicas, o que é declaradamente prioridade para o próprio governo que o elaborou. Argumentamos que a path dependence pode explicar por que a Lei n. 11.096/2005, que instituiu o Prouni, insere-se no modelo institucional histórico de expansão de oferta de cursos de educação superior vigente até hoje no Brasil, focado em instituições de ensino privadas e caracterizado pelo subinvestimento em carreiras estratégicas para o desenvolvimento nacional.
\end{abstract}

\section{PALAVRAS-CHAVE}

Políticas públicas. Prouni. Educação superior. Path dependence. Cursos estratégicos.

\begin{abstract}
In this article we examine the current breakdown of Prouni scholarships per kind of undergraduate course so as to identify the main fields of knowledge that are made available in the higher education market by Prouni and to which extent the program is compatible with the need to foster higher education in strategic fields of knowledge, which is an official priority of the government that designed the program. We argue that path dependence can contribute to explaining why Law No. 11.096/2005, which instituted Prouni, falls within the institutional framework that comprises the growth of higher education supply still existent today in Brazil. This model is focused on private institutions of higher education and is characterized by an underinvestment in fields of knowledge that are strategic for national development.
\end{abstract}

\section{KEYWORDS}

Public policies. Prouni. Higher education. Path dependence. Strategic courses.

SUMÁRIO: Introdução. 1 Acesso à educação superior no Brasil: o contexto em que se insere o Prouni. 2 Os resultados do Prouni. 3 Análise dos resultados do Prouni. 4 Conclusão. Referências.

\footnotetext{
* Bacharel e mestrando em Direito da Regulação pela Fundação Getulio Vargas (FGV Direito Rio, Rio de Janeiro, RJ, Brasil). Advogado.E-mail: joaomarcelocslima@gmail.com

** Doutor e Mestre em Direito pela UERJ. LL.M pela NYU School of Law. Bacharel em Direito pela PUC-RJ. ExSuperintendente-Geral do Conselho Administrativo de Defesa Econômica - Cade. Pesquisador no Centro de Justiça e Sociedade (CJUS) da FGV Direito Rio (Rio de Janeiro, RJ, Brasil). E-mail: carlos.ragazzo@fgv.br

${ }^{* * *}$ Doutor e Mestre em Ciência Política pelo Iuperj. Bacharel em Ciências Sociais pela UFMG. Pesquisador no Centro de Justiça e Sociedade (CJUS) da FGV Direito Rio (Rio de Janeiro, RJ, Brasil). E-mail: leandro.ribeiro@fgv.br
} 


\section{INTRODUÇÃO}

O Programa Universidade para Todos (Prouni ou Programa) é uma política pública de educação criada pelo Ministério da Educação (MEC) durante o primeiro mandato do governo Lula, e tem por objetivo declarado democratizar o acesso ao ensino superior. Graças a ela, milhares de alunos desfavorecidos puderam frequentar um curso de graduação. Por isso, alguns de seus resultados merecem ser explicitados e analisados, pois não é desprezível a quantidade de pessoas que está acessando o ensino superior por meio desse programa. O objetivo deste texto é identificar quais são as principais áreas de conhecimento disponibilizadas no mercado educacional superior pelo Prouni, bem como observar em que medida esse programa se compatibiliza com o estímulo à formação superior em áreas de conhecimento consideradas estratégicas para o desenvolvimento nacional.

Em 25 de setembro de 2013, a presidente Dilma Rousseff apresentou seu plano de investimentos em infraestrutura na sede do banco Goldman Sachs, em Nova York. Nessa reunião, Dilma pronunciou uma frase que a imprensa prontamente repercutiu: “Advogado é custo, engenheiro é produtividade” (TEIXEIRA JR., 2013). Por trás dessa frase, Dilma reafirmou a prioridade da política educacional de seu governo: formar mais cientistas, em prol do desenvolvimento do Brasil. Dilma não está errada. Diversos estudos corroboram a existência de uma forte correlação entre o fortalecimento das carreiras de ciências exatas e tecnologia e o crescimento econômico no longo prazo $^{1}$. Por isso, essas áreas do conhecimento foram definidas pelo atual governo como prioritárias no Programa Ciência sem Fronteiras ${ }^{2}$. Outra carreira definida como estratégica por um polêmico programa $^{3}$ criado pelo governo que instituiu o Prouni é a medicina.

\footnotetext{
${ }^{1}$ Lins et al. (2014), por exemplo, fizeram um levantamento da quantidade de indivíduos formados em carreiras técnicocientíficas em diversos países, e correlacionou esse número ao tamanho da economia desses países. A conclusão a que chegaram os autores é que países com mais pessoas formadas em carreiras técnico-científicas têm melhor desempenho econômico no longo prazo.

${ }^{2}$ De acordo com o art. $1^{\circ}$ do Decreto 7.642/2011, que instituiu esse programa, seu objetivo é: "propiciar a formação e capacitação de pessoas com elevada qualificação em universidades, instituições de educação profissional e tecnológica, e centros de pesquisa estrangeiros de excelência, além de atrair para o Brasil jovens talentos e pesquisadores estrangeiros de elevada qualificação, em áreas de conhecimento definidas como prioritárias” (grifo nosso). O art. $5^{\circ}$, III, c, do referido decreto estabelece que compete ao Comitê de Acompanhamento e Assessoramento do Programa, vinculado ao MEC e ao Ministério da Ciência, Tecnologia e Inovação propor as áreas prioritárias do Programa, que são hoje: engenharias e demais áreas tecnológicas; ciências exatas e da terra; biologia, ciências biomédicas e da saúde; computação e tecnologias da informação; tecnologia aeroespacial; fármacos; produção agrícola sustentável; petróleo, gás e carvão mineral; energias renováveis; tecnologia mineral; biotecnologia; nanotecnologia e novos materiais; tecnologias de prevenção e mitigação de desastres naturais; biodiversidade e bioprospecção; ciências do mar; indústria criativa (voltada a produtos e processos para desenvolvimento tecnológico e inovação); novas tecnologias de engenharia construtiva; formação de tecnólogos.

3 Trata-se do Programa Mais Médicos, instituído pela Lei 12.871/2013. De acordo com as informações do site do programa: “[...] No caso do não preenchimento de todas as vagas, o Brasil aceitará candidaturas de estrangeiros, com a intenção de resolver esse problema, que é emergencial para o país. Os municípios não podem esperar seis, sete ou oito anos para que recebam médicos para atender a população brasileira. Hoje, o Brasil possui 1,8 médicos por mil habitantes. Esse índice é menor do que em outros países, como a Argentina $(3,2)$, Uruguai $(3,7)$, Portugal $(3,9)$ e Espanha $(4)$. Além
}

Revista da Faculdade de Direito - UFPR, Curitiba, vol. 61, n. 3, set./dez. 2016, p. 119 - 139 
O governo entende ser socialmente desejável que se invista na formação de pessoas capacitadas a atuar em carreiras acessíveis para profissionais de áreas como engenharia, medicina, biotecnologia, ciência da computação, entre outras. O investimento é tanto necessário quanto urgente. O Brasil carece de mão de obra formada em engenharia ${ }^{4}$, ciência e tecnologia, como os relatórios da empresa de consultoria Manpower reiteram ano após ano (vide, e.g., BONFANTI; MARTINS, 2012). Há também indícios de que, no Brasil, faltam médicos, enfermeiros e dentistas, e que, ademais, esses profissionais estão geograficamente mal distribuídos (vide, e.g., COLLUCI, 2013).

O problema é que as instituições de ensino superior brasileiras (IES) não formam profissionais “estratégicos” na mesma quantidade que são formados bacharéis em direito, administradores de empresas e pedagogos. De acordo com o Censo da Educação Superior 2013 do Instituto Nacional de Estudos e Pesquisas Educacionais Anísio Teixeira (Inep), a esmagadora maioria dos concluintes de cursos de graduação, algo em torno de 45\%, formou-se em cursos da Área Geral OCDE ${ }^{5}$ “ciências sociais, negócios e direito”. Apenas 8,2\% dos concluintes se formaram em cursos da Área Geral OCDE “engenharia, produção e construção”, e 14,1\% em cursos de “saúde e bem estar social”6.

A Lei n. 11.096/2005 (BRASIL, 2005), que instituiu o Prouni, pode não estar conseguindo se desvencilhar dessa desproporção, característica do mercado de educação superior brasileiro. Embora o objetivo declarado do Prouni não seja o de direcionar a formação superior para tais áreas, uma possível consequência não prevista do Programa é a reprodução de uma matriz de expansão baseada em cursos de ciências sociais aplicadas, o que estaria em contradição com a atual demanda por mão de obra da economia brasileira, e também em descompasso com as demandas de uma economia cada vez mais baseada no conhecimento e na inovação tecnológica. Este texto se dedicará a analisar se essa é de fato uma consequência do Prouni. Para tanto, serão analisados: (i) o padrão histórico de expansão de oferta de educação superior no Brasil desde o final da década de 1960; (ii) as regras que regem a distribuição das bolsas ofertadas pelo Programa por curso de graduação; e (iii) a efetiva distribuição de bolsas ofertadas entre 2012 e 2014. Essa análise se justifica, pois, caso o nosso diagnóstico sobre a expansão de formação superior proporcionada pelo Prouni seja confirmado, políticas públicas complementares poderão ser elaboradas para suprir essa necessidade de formação

da carência dos profissionais, o Brasil sofre com uma distribuição desigual de médicos nas regiões - 22 estados possuem número de médicos abaixo da média nacional”. Disponível em: <http://goo.gl/nW50nO>. Acesso em: 10 nov. 2014.

${ }^{4}$ Há pesquisas que refutam a hipótese de que faltam engenheiros no País. Esses estudos sustentam que o que existe hoje, na verdade, é uma falta de engenheiros qualificados e especializados para atuar em algumas indústrias específicas (vide, e.g., LINS, 2014).

${ }^{5}$ Organização para a Cooperação e Desenvolvimento Econômico.

6 Dados extraídos da apresentação do Inep "Resultados do Censo da Educação Superior”, disponível em: <http://goo.gl/EkNCg7>. Acesso em: 11 jun. 2015. 
em cursos estratégicos.

\section{ACESSO À EDUCAÇÃO SUPERIOR NO BRASIL: O CONTEXTO EM QUE SE INSERE O PROUNI}

Como mencionado acima, o Prouni foi concebido pelo MEC, redator da Exposição de Motivos da Medida Provisória n. 213/2004 (BRASIL, 2004), que instituiu o Programa e foi posteriormente convertida em lei. Pela redação da Exposição de Motivos, o Prouni é "uma política de acesso democrático ao ensino superior”, ou, em melhores termos, “um programa de democratização do ensino superior mediante a concessão de bolsas de estudo”7 .

Em 2012, o Prouni teve sua constitucionalidade confirmada pelo Supremo Tribunal Federal (STF) em sede de controle constitucional abstrato ${ }^{8}$. O STF entendeu que o Prouni é uma importante ferramenta de inclusão social, perfeitamente compatível com uma série de dispositivos da Constituição brasileira. Não ofende, portanto, o princípio constitucional da isonomia, embora tenha seu escopo limitado a alunos oriundos de camadas desfavorecidas da sociedade. Mas por que foi necessário criar uma política pública como o Prouni no Brasil, a qual, embora focada em alunos desfavorecidos, é dependente da adesão de IES privadas? Como o modelo de acesso ao ensino superior do Prouni se relaciona com as características do setor de educação superior no Brasil?

\subsection{A ESTRATÉGIA DE EXPANSÃO DA EDUCAÇÃO SUPERIOR NOS ANOS 1960 A 1990}

Em 28 de novembro de 1968, para atender às necessidades que se fizeram presentes em razão do aumento de demanda efetiva por cursos superiores e do desenvolvimento econômico (e, consequentemente, às exigências do mercado de trabalho), foi promovida a Reforma Universitária Lei n. 5.540/1968 (BRASIL, 1968). A partir de então, o Estado brasileiro passou a implementar políticas centradas em investimentos em educação superior (SOUZA, 1981). Até o começo da década de 1960, a educação superior não chegava a atender 100.000 alunos, mas, entre 1960 e 1967, registrou-se um crescimento médio de 12,5\% ao ano no número de matrículas (CARVALHO, 2011, p. 276). Nos anos de 1970, diante da necessidade de incluir um grande número de alunos brasileiros

\footnotetext{
${ }^{7}$ Exposição Interministerial n. 061/2004/MEC/MF.

${ }^{8}$ ADI 3330, ajuizada pela Confederação Nacional dos Estabelecimentos de Ensino (Confenen) e à qual foi anexada a ADI 3314, proposta pelo partido DEM. A Confenen argumentou que a medida provisória e a lei em que foi convertida ofendem o artigo 62 da Constituição Federal (CF) e o princípio da separação dos Poderes, consagrado no artigo $2^{\circ}$ da CF. Sustentou, ainda, que os artigos 10 e 11 da lei impugnada violam os artigos 146, II, e 195, parágrafo $7^{\circ}$, da CF, por invadirem seara reservada à lei complementar. E, o que é mais importante, alegou-se que o Programa representava ofensa ao princípio da igualdade. A maior parte dos ministros se concentrou em refutar a alegação de violação ao princípio da isonomia.
}

Revista da Faculdade de Direito - UFPR, Curitiba, vol. 61, n. 3, set./dez. 2016, p. 119 - 139 
(aprovados em vestibulares, mas impossibilitados de ingressar em IES por falta de vagas), o segmento da educação superior sofreu um processo de expansão maciço, subsidiado pelo Estado e embalado pelo milagre econômico ${ }^{9}$.

Em razão desse processo de expansão em massa do ensino superior, as IES privadas ganharam importância e passaram a ser consideradas importantes componentes da política brasileira de educação superior (SAMPAIO, 2000). Mas não foi apenas o Estado que passou a se interessar por universidades particulares, que começaram a albergar o "excedente" de alunos que universidades públicas não tinham como comportar: o segmento da educação superior tornou-se, a partir de então, altamente atrativo para empresários, que nele enxergavam um negócio lucrativo. Essa é uma das explicações para o fato de a expansão dos anos de 1970 ter sido marcada por uma profunda assimetria nas taxas de crescimento. Enquanto o segmento público de IES ampliou em aproximadamente 16\% ao ano o número de alunos matriculados, o segmento privado registrou um impressionante crescimento de 31\% ao ano (CARVALHO, 2011, p. 277).

A lucratividade da indústria de educação superior resultava da estratégia dos governos militares, a qual consistia na concessão de incentivos e isenções fiscais para apoiar a atuação privada “no projeto de desenvolvimento nacional, beneficiando uma ampla gama de setores em diferentes áreas” (CARVALHO; LOPREATO, 2005, p. 199). A Constituição de 1967 estabelecia a não incidência de impostos sobre renda, patrimônio e serviços dos estabelecimentos de ensino de qualquer natureza, o que levou as IES privadas a gozarem de imunidade fiscal desde sua criação. No entanto, entre 1980 e 1994 - período que engloba o fim do regime autoritário e o início do processo de redemocratização -, o segmento privado apresentou baixíssimo aumento de matrículas. Mais especificamente, em 1981, 1984/1985 e 1991, houve queda no número de matrículas privadas, enquanto as públicas cresceram a taxas módicas. A rede predominante era, naquela época e ainda hoje, aquela constituída pelas IES privadas.

\subsection{O GOVERNO FHC E O PRIMEIRO PLANO NACIONAL DA EDUCAÇÃO}

O fôlego estatal para resolver essa crise do ensino superior atingiu seu ápice no início da década de 2000, quando o governo Fernando Henrique Cardoso (FHC) promulgou o Plano Nacional da Educação (PNE), Lei n. 10.172, de 9 de janeiro de 2001 (BRASIL, 2001). Essa lei, cuja atenção se voltava à educação brasileira em geral, evidenciava uma preocupação bastante clara quanto ao

\footnotetext{
${ }^{9}$ Carvalho mostra como, entre 1968 e 1974, o ciclo expansivo do segmento de educação superior foi extremamente intenso, levando à extraordinária expansão de aproximadamente 24\% ao ano (CARVALHO, 2002, p. 118).
} 
futuro da educação superior do País: “como resultado conjugado de fatores demográficos, aumento das exigências do mercado de trabalho, além das políticas de melhoria do ensino médio, prevê-se uma explosão na demanda por educação superior” (BRASIL, 2001). O PNE foi bastante ambicioso ao estabelecer suas metas para a educação superior no Brasil. Almejava-se que, até 2010, 30\% dos jovens entre 18 e 24 anos estivessem matriculados em cursos desse nível de ensino no País ${ }^{10}$.

A meta tinha sua razão de ser. O setor de educação superior, por mais que tenha sido, ao longo de sua história, beneficiado pelo Estado, que tinha interesse na sua expansão, adentrou o século XXI atendendo a pouquíssimos jovens. O Censo Pnad/Instituto Brasileiro de Geografia e Estatística (IBGE) de 2004 revelou que apenas 10,63\% dos jovens brasileiros entre 18 e 24 anos de idade frequentavam cursos de ensino superior, contra 67,83\% de jovens dessa faixa etária que não frequentavam nível de ensino algum. O mesmo censo também mostrou que, em 2004, apenas 33,02\% dos estudantes entre 18 e 24 anos estavam matriculados em cursos de educação superior, enquanto 47,56\% se encontravam ainda no nível médio. Por mais que não fosse razoável esperar que todos os brasileiros entre 18 e 24 estivessem frequentando cursos de educação superior (ou que todos os estudantes entre 18 e 24 estivessem nesse nível de ensino), os números do Pnad/IBGE indicavam que, em 2004, o acesso à educação superior era reservado a pouquíssimos jovens ${ }^{11}$, ainda mais se compararmos nossos números com os dos demais países da América Latina ${ }^{12}$ e do mundo ${ }^{13}$.

Em 2001, esse cenário de desigualdade de acesso ao ensino superior era bastante evidente: o IBGE revelou que as classes desfavorecidas praticamente não frequentavam nem universidades públicas, nem privadas ${ }^{14}$. Era preciso lidar com esse problema e, como vimos acima, o PNE já havia ditado uma meta de acesso ao ensino superior bastante ambiciosa. O governo havia, originalmente, planejado lidar com o déficit de acesso jovem ao ensino superior - e honrar a sua meta prevista no PNE - via incremento de gastos públicos com educação, que, segundo a proposta original do PNE,

\footnotetext{
${ }^{10}$ Não obstante a meta fixada, segundo a Síntese dos Indicadores Sociais, publicada pelo IBGE no final de 2009, apenas 13,7\% da população daquela faixa etária cursava a educação superior no Brasil (IBGE, 2009).

11 Essa constatação é ainda mais importante se analisarmos os dados de distribuição segundo níveis de ensino (fundamental, médio, pré-vestibular e superior) por região geográfica no Brasil. O Pnad/IBGE revelou, em 2003, que enquanto 48,6\% dos estudantes entre 18 e 24 anos no Sul do País frequentavam cursos de educação superior, no Sudeste esse número era de 41\%; no Nordeste, apenas 15,4\%; e no Norte, 16,7\% (NEVES, 2007, p. 153).

${ }^{12}$ Segundo dados do Instituto Internacional da Unesco (Organização das Nações Unidas para a Educação, a Ciência e a Cultura) para a Educação Superior na América Latina e Caribe (Iesalc/Unesco) e da Base de Estatísticas e Indicadores Sociais da Comissão Econômica para a América Latina e Caribe (BADEINSO/CEPAL), em 2003 a taxa bruta de acesso ao ensino superior era de 59,8\% na Argentina, 42,4\% no Chile, 39,4\% na Bolívia e de apenas 20\% no Brasil. Dos países da América Latina, apenas a Guiana (6,1\%) perdeu para o Brasil no ranking (NEVES, 2007, p. 141).

${ }^{13}$ De acordo com dados da OCDE, a taxa de acesso à educação superior da população entre 18 e 24 era, em 2004 , de 32,6\% na Alemanha, 53,1\% na Argentina, 65,4\% na Bélgica, 55,9\% na Austrália, 65\% nos Estados Unidos, 29,9\% na Suíça, 24,8\% no México e de apenas 10,6\% no Brasil (NEVES, 2007, p. 141).

${ }^{14}$ O IBGE mostrou, inclusive, que universidades privadas albergavam 50\% dos $10 \%$ mais ricos da população brasileira, enquanto universidades públicas albergavam 34,4\% dessa parcela mais abastada da população (IBGE, 2003).
} 
deveriam atingir o mínimo de 7\%. Relatam Pacheco e Ristoff (2004) que isso exigia uma ampliação dos recursos à razão de $0,5 \%$ do PIB, anualmente, nos primeiros anos do Plano, e de 0,6\% no quinto ano. Entretanto, essa meta foi vetada pelo presidente à época, FHC. Como resultado, observam os autores, “a ampliação expressiva das vagas pelo poder público ficou seriamente comprometida, passando a expansão a depender quase exclusivamente da força do mercado” (PACHECO; RISTOFF, 2004, p. 6).

Assim, a gestão FHC passou a tratar o crescimento da demanda potencial por ensino superior - impulsionado, entre outras razões, pela melhoria das condições da população brasileira em razão da estabilidade econômica de seu governo (CARVALHO, 2011, p. 280) - via incentivos à iniciativa privada, com a chancela do Conselho Nacional de Educação (CNE) ${ }^{15}$. O CNE encorajou a abertura de novos cursos em locais isolados, bem como a criação de mais IES (CARVALHO, 2011, p. 281). A iniciativa privada, por sua vez, não perdeu a janela de oportunidade aberta pelo Estado, razão pela qual o governo FHC foi marcado pela revitalização da expansão do segmento de ensino superior privado, após forte período de estagnação durante os anos 80 e começo dos anos 90. De fato, entre 1995 e 2002 o segmento privado apresentou incremento na oferta de cursos em torno de $14 \%$ ao ano, enquanto o público (federal) cresceu apenas $8 \%$ ao ano ${ }^{16}$.

Bertolin atribui esse processo também à pressão ideológica de organismos multilaterais, como o Banco Mundial, que em 1998 publicou relatório concluindo que a educação superior é antes um bem privado do que público, razão pela qual deveria ser tratada como serviço comercial, sujeito à livre concorrência e à regulação econômica (BERTOLIN, 2011, p. 243). Uma das manifestações dessa ideologia foi a aprovação, no final da década de noventa - e, portanto, já durante a gestão FHC - da Lei n. 9.870/1999 (BRASIL, 1999). Essa lei permitiu que as IES pudessem ter finalidade lucrativa (natureza mercantil), e possibilitou que elas se organizassem sob qualquer das modalidades existentes no Código Civil. Edson Nunes, ex-presidente do CNE, observa que a Lei 9.870/1999, além de ser o resultado de pressões regulares do setor privado, teve por objetivo "criar um incentivo para adesão aos programas de bolsas públicas e outras iniciativas governamentais. As instituições com finalidade mercantil têm a vantagem de abatimento de impostos” (BIZONI, 2013).

\footnotetext{
${ }^{15}$ A participação pública no ensino superior começou a retrair com a gestão FHC. Se no começo do primeiro mandato de FHC o segmento federal detinha $21 \%$ do total de matrículas em IES, em 2002 (final do segundo mandato) essa percentagem havia caído para apenas $15 \%$.

${ }^{16}$ A explosão de oferta do ensino superior privado fica especialmente evidente se considerarmos a divisão entre instituições privadas lucrativas e não lucrativas, que passou a existir desde 1999, pela qual se observa, entre 1999 e 2002, um crescimento médio de 28,5\% ao ano (CARVALHO, 2011, p. 281).
} 


\subsection{A EDUCAÇÃO SUPERIOR NO GOVERNO LULA E A ELABORAÇÃO E IMPLEMENTAÇÃO DO PROUNI}

Após anos de aceleração do crescimento do segmento de ensino superior privado, o ritmo de expansão das matrículas reduziu-se com a chegada de Lula ao poder, em $2003^{17}$. Uma razão para essa desaceleração reside no diagnóstico, feito pelo governo Lula, de que a expansão pela via privada não resolveu o problema da baixa escolaridade (média e superior) no Brasil (CARVALHO, 2011, p. 283). Por isso, a chamada Reforma Universitária do governo Lula - uma série de discussões e propostas para promover a democratização do acesso à educação superior brasileira oriunda de seu programa de governo - baseou-se em três eixos centrais: (i) expansão da universidade pública gratuita; (ii) revisão do mecanismo de financiamento estudantil; e (iii) concessão de bolsas de estudo (HADDAD; BACHUR, 2004).

Entre os primeiros passos da Reforma estava a edição de medidas que, simultaneamente, suprissem a necessidade de expansão da rede de ensino superior e não onerassem a União (MANCEBO, 2004, p. 80). É nesse contexto que se insere o Prouni, lançado em 2004. Trata-se, assim, tanto de medida reparatória focada em classes desfavorecidas da população, quanto de medida inserida na agenda estatal de expansão da oferta de ensino superior. O desafio era promover ambos os objetivos e, ao mesmo tempo, onerar os cofres públicos o mínimo possível.

A solução encontrada pelos formuladores do Prouni foi recorrer às IES privadas, cuja expansão havia sido estimulada pelo Estado em anos anteriores e, especialmente, a partir da Lei n. 9.870/1999. É por isso que o funcionamento do Prouni depende da (i) alta ociosidade característica do ensino superior privado (em 2002, 35\% das vagas; em 2003, 42\%; e em 2004, 49,5\%), bem como de (ii) atrativas isenções fiscais para as IES privadas aderentes ao Programa. Essa engenharia jurídicofinanceira do Prouni parece ser altamente benéfica para as contas públicas; referindo-se ao primeiro ano do Prouni, Almeida (2007, p. 86) estimou a renúncia fiscal em R\$ 50 milhões, contra R\$ 340 milhões para gerar o mesmo número de vagas em IES públicas. Por isso, o Prouni seria uma política pública de acesso ao ensino superior com baixo custo para o governo (CATANI et al., 2006, p. 127).

\subsection{O FUNCIONAMENTO DO PROUNI}

As bolsas do Prouni são destinadas a estudantes que tenham cursado o ensino médio completamente em escolas da rede pública, ou em instituições privadas como bolsistas integrais, bem

\footnotetext{
${ }^{17}$ No caso das instituições privadas sem fins lucrativos, essa diminuição de ritmo beirou a estagnação: enquanto no governo FHC as matrículas nesse setor cresciam a, aproximadamente, 10\% ao ano, durante o governo Lula o crescimento foi inferior a 3\% ao ano e abaixo do incremento do segmento público federal (CARVALHO, 2011, p. 282).
}

Revista da Faculdade de Direito - UFPR, Curitiba, vol. 61, n. 3, set./dez. 2016, p. 119 - 139 
como a estudantes portadores de deficiências e a professores da rede pública de ensino (para cursos de licenciatura, normal superior e pedagogia, independentemente de renda). Trata-se de benefício concedido pelo governo federal a estudantes, e não está condicionado a qualquer forma de restituição financeira ao governo (AMARAL; OLIVEIRA, 2011a, p. 27). Os bolsistas, que devem cumprir requisitos de desempenho acadêmico estabelecidos pelo MEC, são selecionados da seguinte forma: (i) em primeiro lugar, são pré-selecionados pelos resultados e perfil socioeconômico do Exame Nacional do Ensino Médio - ou por outros critérios sujeitos à definição do MEC - e, subsequentemente, (ii) escolhidos pela IES almejada, segundo critérios internos. À IES compete aferir a veracidade das informações prestadas pelo candidato.

Os bolsistas do Prouni estão autorizados a transferir a utilização de suas bolsas de estudo para outro curso, mesmo que em outro turno, campus ou até mesmo outra IES. Os prounistas podem, também, trancar a matrícula de acordo com as normas da IES, solicitando, para tanto, a suspensão do usufruto da bolsa. Entretanto, o período em que a bolsa estiver suspensa se converte em efetiva utilização, sendo descontado do seu prazo total de utilização. Para continuar usufruindo do Prouni, os bolsistas devem ser aprovados em, no mínimo, 75\% das disciplinas cursadas em cada período letivo. Cabe notar, ainda, que é vedada à IES cobrar dos bolsistas integrais as matérias cursadas novamente em razão de reprovação.

Visando garantir a continuidade de estudo dos bolsistas, criou-se a Bolsa Permanência, de até R\$ 300,00 mensais, voltada apenas para beneficiários do Prouni com bolsa integral não suspensa, matriculados em cursos presenciais com, no mínimo, seis semestres de duração, e cuja carga horária média seja igual ou superior a seis horas diárias de aula. A concessão da Bolsa Permanência está condicionada à disponibilidade orçamentária e financeira do MEC.

As obrigações a serem cumpridas pelas IES aderentes ao Prouni devem estar previstas em um termo de adesão, no qual são imprescindíveis as seguintes cláusulas: (i) número de bolsas de estudo oferecidas por curso, turno e unidade; (ii) percentual de bolsas de estudo destinado à implementação de políticas afirmativas de acesso ao ensino superior de portadores de deficiência ou indígenas e negros autodeclarados - esse percentual deve ser igual ao de cidadãos autodeclarados indígenas, pardos ou negros, na respectiva Unidade da Federação, de acordo com o último censo do IBGE divulgado. Durante o período de vigência do termo de adesão, as IES aderentes estão isentas do recolhimento das seguintes contribuições e impostos: (i) Contribuição para o Financiamento da Seguridade Social; (ii) Contribuição para o Programa de Integração Social; (iii) Contribuição Social sobre o Lucro Líquido; (iv) Imposto de Renda da Pessoa Jurídica. 


\section{OS RESULTADOS DO PROUNI}

Os estudos que avaliam o desempenho do Prouni desde sua criação mostram que os resultados são positivos. Pesquisas recentes mostram que o Programa contribui para a empregabilidade de seus beneficiários, sendo possível comprovar sua eficácia a partir de demonstrações de baixa taxa de evasão e do aumento significativo de trajetórias profissionais e pessoais de seus egressos (AMARAL; OLIVEIRA, 2011b, p. 861). Dois anos antes da publicação da pesquisa de Amaral e Oliveira, o MEC encomendou uma pesquisa ao Instituto Brasileiro de Opinião Pública e Estatística (Ibope), em que foram ouvidos 1.200 recém-formados beneficiários do Prouni em estados de todas as regiões do País (MEC, 2009). De acordo com a pesquisa, 80\% dos entrevistados informaram que estavam terminando seus cursos superiores e se encaminhariam em seguida a um emprego garantido (esse índice correspondia a 56\% antes de os estudantes entrarem no Programa). Ou seja, conforme a pesquisa do Ibope, o Prouni aumentou em 43\% a empregabilidade de seus beneficiários. Interessa também notar que, segundo essa pesquisa, 68\% dos entrevistados afirmaram que a renda de suas famílias aumentou desde a entrada na faculdade. Desses 68\%, a maioria - $40 \%$ - classificou o aumento de renda como “pequeno". O restante - $28 \%$ - afirmou que a renda familiar aumentou “muito”.

Não há como desprezar, portanto, o valor do Prouni, capaz de transformar a vida de seus beneficiários, viabilizando assim um certo grau de mobilidade social no País. Mas as externalidades positivas do Prouni não são aproveitadas diretamente por toda a sociedade brasileira, nem beneficiam necessariamente todos os setores da economia, como aqueles em que há carência de mão de obra qualificada e que são estratégicos para o desenvolvimento do País. O impacto do Programa tem, de fato, escopo limitado, nos termos explorados abaixo.

\subsection{A ABRANGÊNCIA DO PROUNI}

Os números globais de bolsas ofertadas pelo Prouni nos últimos anos indicam que há uma certa estabilidade no número total de bolsas ofertadas por ano desde 2009 (embora 2012 tenha fugido à regra). Os números dos últimos anos não parecem indicar uma tendência de ampliação do número de bolsas ofertadas anualmente. Isso sugere que o Programa já se difundiu entre as IES privadas hoje autorizadas a oferecer cursos de ensino superior no Brasil, o que é particularmente o caso considerando que, em 2013, havia um total de 2.090 IES privadas no País, de acordo com o Censo da Educação Superior. A quantidade de bolsas oferecidas pelo Programa parece ter se estabilizado na

casa dos 250.000. É razoável esperar que esse número só aumente substancialmente quando novas

Revista da Faculdade de Direito - UFPR, Curitiba, vol. 61, n. 3, set./dez. 2016, p. 119 - 139 
IES se habilitarem a participar do Prouni.

Tabela 1 - Abrangência do Prouni em números.

\begin{tabular}{|c|c|c|c|}
\hline Ano & Semestre & IES com oferta de bolsas do & Número de bolsas \\
\hline 2005 & - & 1.132 & 112.275 \\
\hline 2006 & $1^{\circ}$ & 1.150 & \multirow{2}{*}{138.668} \\
\hline 2006 & $2^{\circ}$ & 791 & \\
\hline 2007 & $1^{\circ}$ & 1.206 & \multirow{2}{*}{163.854} \\
\hline 2007 & $2^{\circ}$ & 877 & \\
\hline 2008 & $1^{\circ}$ & 1.227 & \multirow{2}{*}{225.005} \\
\hline 2008 & $2^{\circ}$ & 1.001 & \\
\hline 2009 & $1^{\circ}$ & 1.249 & \multirow{2}{*}{247.643} \\
\hline 2009 & $2^{\circ}$ & 993 & \\
\hline 2010 & $1^{\circ}$ & 1.302 & \multirow{2}{*}{241.273} \\
\hline 2010 & $1^{\circ}$ & 971 & \\
\hline 2011 & $1^{\circ}$ & 1.273 & \multirow{2}{*}{254.598} \\
\hline 2011 & $2^{\circ}$ & 1.035 & \\
\hline 2012 & $1^{\circ}$ & 1.319 & \multirow{2}{*}{284.622} \\
\hline 2012 & $2^{\circ}$ & 1.041 & \\
\hline 2013 & $1^{\circ}$ & 1.078 & \multirow{2}{*}{252.374} \\
\hline 2013 & $2^{\circ}$ & 919 & \\
\hline
\end{tabular}

Fonte: elaboração própria a partir de dados do SisProuni, disponibilizados pelo MEC via e-SIC.

\subsection{A DISTRIBUIÇÃO DAS BOLSAS DO PROUNI POR CURSO}

Os dados da seção 2.1, acima, parecem indicar que o Prouni alcança, hoje, um número significativo de pessoas desfavorecidas. Em termos numéricos, o Programa parece ter sido exitoso, particularmente para o que se propõe a promover: a igualdade material de acesso de pessoas desfavorecidas ao ensino superior. A pergunta que, no entanto, os números acima não respondem, é: a que cursos os prounistas têm acesso? Será que eles têm oportunidades iguais de estudar, por exemplo, direito ou administração, em comparação a medicina ou engenharia?

Para responder a essa pergunta, vale verificar a distribuição de bolsas do Prouni por curso nos últimos anos, o que foi possível apenas por meio da apresentação de pedidos de informação na plataforma e-SIC. Em resposta aos pedidos, o MEC forneceu uma lista completa de bolsas por curso ofertadas pelo Programa, a partir do SisProuni (banco de dados do Prouni). Ao analisar o documento, observa-se que a oferta de bolsas do Prouni é extremamente diversificada. De fato, as IES aderentes ao Programa ofertaram, ao longo de sua história (2005-2014), desde bolsas em cursos “tradicionais”, como direito, economia, administração, medicina e diversas engenharias, até bolsas (em número de cinco, em 2011) para o curso superior “produtores e músicos de rock”, por exemplo. Todos esses cursos entram na conta das "bolsas ofertadas pelo Prouni” anunciadas pelo governo. Assim sendo, 
parece que qualquer conclusão baseada em dados de representatividade das bolsas de cada curso deva ser lida com certo tempero, pois o cálculo do universo de bolsas do Programa envolve uma série de cursos atípicos que são ofertados, os quais não são necessariamente ocupados por beneficiários do Programa.

Tabela 2 - Distribuição das bolsas do Prouni por cursos estratégicos e não estratégicos.

\begin{tabular}{c|c|c|c}
\hline Curso de ensino superior & $\begin{array}{c}\mathbf{N}^{\mathbf{0}} \text { de bolsas ofertadas } \\
\text { em 2012 }\end{array}$ & $\begin{array}{c}\mathbf{N}^{\mathbf{0}} \text { de bolsas } \\
\text { ofertadas em 2013 }\end{array}$ & $\begin{array}{c}\mathbf{N}^{\mathbf{0}} \text { de bolsas ofertadas no } \\
\text { primeiro semestre de 2014 }\end{array}$ \\
\hline Administração & 34.721 & 29.695 & 21.281 \\
\hline Direito & 18.612 & 17.834 & 13.794 \\
\hline Engenharia $^{18}$ & $20.496^{19}$ & $22.650^{20}$ & $19.837^{21}$ \\
\hline Ciências biológicas $^{22}$ & $5.555^{23}$ & $5.040^{24}$ & $1.921^{25}$ \\
\hline Medicina & 1.059 & 1.021 & 693 \\
\hline Geologia & 32 & 33 & 37 \\
\hline Ciência da computação & 2.326 & 2.201 & 1.737 \\
\hline
\end{tabular}

Fonte: elaboração própria a partir de dados do SisProuni de 2012, 2013 e 2014, disponibilizados pelo MEC via e-SIC.

A Tabela 2 retrata o atual cenário de distribuição de bolsas do Prouni, razão pela qual escolhemos dados de 2012, 2013 e do primeiro semestre de 2014. Ao ler a tabela (e suas respectivas notas de rodapé), é possível identificar importantes limitações metodológicas. Em primeiro lugar, a categoria “engenharia” é extremamente abrangente, englobando desde engenharia mecatrônica até engenharia de segurança no trabalho. Alguns cursos poderiam estar englobados no conceito de

\footnotetext{
${ }^{18}$ Os cursos classificados como "engenharia" são todos aqueles indicados como "engenharia de X, Y ou Z" na planilha do SisProuni que nos foi fornecida. Exatamente quais cursos são esses varia de ano a ano, de acordo com a oferta das IES aderentes ao Prouni. Dessa forma, abre-se nota de rodapé para esclarecer que cursos são esses, exatamente, por ano.

19 Em 2012, os cursos considerados como "engenharia" foram: engenharia; engenharia aeronáutica; engenharia aeronáutica e espaço; engenharia agrícola; engenharia agrícola e ambiental; engenharia agronômica; engenharia ambiental; engenharia ambiental e energias renováveis; engenharia ambiental e sanitária; engenharia automotiva; engenharia bioenergética; engenharia biomédica; engenharia civil e ambiental; engenharia civil; engenharia da computação; engenharia de alimentos; engenharia de automoção e controle; engenharia de bioprocessos; engenharia de bioprocessos e biotecnologia; engenharia de computação; engenharia de controle e automoção; engenharia de energia; engenharia de materiais; engenharia de minas; engenharia de petróleo; engenharia de petróleo; engenharia de produção; engenharia de produção agroindustrial; engenharia de petróleo e gás; engenharia de produção agroindustrial; engenharia de produção e qualidade; engenharia de produção mecânica; engenharia de segurança no trabalho; engenharia de software; engenharia de telecomunicações; engenharia elétrica; engenharia eletrônica; engenharia eletrônica e de telecomunicação; engenharia em nanotecnologia; engenharia florestal; engenharia industrial mecânica; engenharia mecânica; engenharia mecânica automotiva; engenharia mecatrônica; engenharia metalúrgica e engenharia química.

${ }^{20}$ Em 2013, os cursos considerados como "engenharia" foram os mesmos que em 2012, com exceção de engenharia de agrimensura e engenharia cartográfica e de agrimensura.

${ }^{21}$ Em 2014, os cursos considerados como "engenharia” foram os mesmos que em 2013.

22 Os cursos classificados como "ciências biológicas" são todos aqueles indicados na planilha do SisProuni como sendo ligados, pelo nome, à biologia, biotecnologia, bioenergia, etc. Esses cursos também variam de ano a ano.

${ }^{23}$ Em 2012, os cursos considerados como "ciências biológicas" foram os seguintes: bioenergia; biologia; biomedicina; biotecnologia; biotecnologia industrial; ciências biológicas e ciências biológicas - modalidade médica.

${ }^{24}$ Em 2013, os cursos considerados como "ciências biológicas" foram os seguintes: bioenergia; biologia; biomedicina; biotecnologia; biotecnologia industrial e ciências biológicas.

${ }^{25}$ Em 2014, os cursos considerados como “ciências biológicas” foram os mesmos que em 2013.
} 
ciências biológicas, como "engenharia bioenergética” ou “engenharia biomédica”. E outros, como “engenharia de software”, poderiam ser de ciência da computação. Mesmo diante dessa limitação, é possível deduzir algumas conclusões, mesmo que preliminares.

A primeira delas, que salta aos olhos, é que a oferta de bolsas do Prouni parece estar bastante concentrada em administração e direito. Por exemplo, das 191.625 vagas ofertadas no primeiro semestre de 2014, 35.075 foram para esses cursos, o que representa 18,3\% do total de cursos ofertados. Em 2013, a representatividade de administração e direito em relação ao total de vagas oferecidas foi de 18,33\%, número muito parecido ao do primeiro semestre de 2014. Já em 2012, esse número foi de aproximadamente $18,73 \%$. Por outro lado, ao agruparmos as bolsas concedidas para os cursos estratégicos da Tabela 2 acima (engenharia, ciências biológicas, medicina, geologia e ciência da computação), notamos que, em 2014, eles correspondiam a apenas 12,64\% do total de bolsas ofertadas. Em 2013, esse número não foi muito diferente: 12,02\%. E, em 2012, cerca de 10\%.

\section{ANÁLISE DOS RESULTADOS DO PROUNI}

As bolsas ofertadas para administração e direito vêm representando, nos últimos três anos, entre seis e oito pontos percentuais a mais do que o conjunto de bolsas para cursos estratégicos engenharia, ciências biológicas, medicina, geologia e ciência da computação. O que terá causado essa desproporção nas bolsas, por curso, do Prouni?

\subsection{COMO É FEITA A DISTRIBUIÇÃO, POR CURSO, DE BOLSAS DO PROUNI?}

A já comentada Lei n. 11.096/05, que instituiu o Prouni, define, em seus artigos $5^{0}$ e 10, como deve ser feita a distribuição de bolsas por curso universitário. De acordo com os referidos artigos, as instituições participantes do Prouni devem oferecer as bolsas do Programa em todos os seus cursos e turnos, na seguinte proporção:

(i) Instituição privada de ensino superior com fins lucrativos ou sem fins lucrativos não beneficente: uma bolsa integral para o equivalente a 10,7 estudantes regularmente pagantes e devidamente matriculados, em cursos efetivamente instalados, ou uma bolsa integral para cada 22 estudantes regularmente pagantes e devidamente matriculados em cursos efetivamente instalados, desde que a IES ofereça, adicionalmente, quantidade de bolsas parciais - de $50 \%$ ou de $25 \%$ - na proporção necessária para que a soma dos benefícios concedidos atinja o equivalente a 8,5\% da receita anual dos períodos letivos que já têm 
bolsistas do Prouni.

(ii) Instituição privada de ensino superior beneficente de assistência social: uma bolsa integral para o equivalente a nove estudantes regularmente pagantes e devidamente matriculados, em cursos efetivamente instalados.

Os dispositivos mencionados acima dão a (falsa) impressão de que os prounistas têm acesso, a cada ano, a um amplo leque de cursos. Antes do Prouni, as instituições sem fins lucrativos concediam bolsas de estudos com subsídios estatais, mas “eram elas que definiam os beneficiários, os cursos, o número de bolsas e os descontos concedidos, consequentemente, raramente era concedida bolsa integral e quase nunca em curso de alta demanda” (CUNHA et al., 2014, p. 42). Atualmente, assinando o termo de adesão, a IES aderente ao Prouni se compromete a conceder, observadas as proporções descritas em (i) e (ii) acima, bolsas em todos os seus cursos instalados e autorizados, sem exceção. Assim, o Prouni parece ter sido concebido sob a influência de uma experiência considerada problemática - a da época em que IES privadas sem fins lucrativos tinham plena discricionariedade para selecionar as bolsas que concederiam - e ter sido proposto de modo a corrigi-la. Afinal, a discricionariedade do período pré-Prouni implicava, entre outras coisas, o subdimensionamento de alguns cursos de alta demanda. Porém, como explicar tamanha diferença entre a quantidade de bolsas concedidas para direito e administração e das que são oferecidas para medicina, engenharia, etc.? Para responder, é necessário analisar a estrutura do Prouni, bem como algumas peculiaridades do mercado de educação superior.

\subsection{IMPACTO DAS DIFERENTES ESTRUTURAS DE CUSTOS DE CURSOS DE EDUCAÇÃO SUPERIOR EM OCIOSIDADE}

O funcionamento do Prouni é dependente de duas variáveis: (i) a alta capacidade ociosa dos cursos de educação superior oferecidos por IES privadas; e (ii) a atratividade das isenções fiscais de que se beneficiam as IES privadas como contrapartida pela concessão das bolsas. Embora o grau de ociosidade de vagas no ensino superior privado seja alto no agregado - em 2009, por exemplo, 41,8\% das vagas do segmento não foram ocupadas (QUEIROZ et al., 2013, p. 367) -, ele varia significativamente conforme o curso. Isso porque cursos estratégicos têm estruturas de custos muito diferentes das de cursos não estratégicos (o custo marginal e médio de um aluno de um curso estratégico como medicina ou engenharia é substancialmente maior do que o custo de um aluno 
cursando direito ou administração, por exemplo) ${ }^{26}$.

Não se trata de informação contraintuitiva. Basta pensar na quantidade e no preço dos materiais e da infraestrutura (laboratórios de ensino e pesquisa, por exemplo) que se fazem necessários para que alunos de medicina tenham uma experiência acadêmica decente ${ }^{27}$. Por outro lado, um aluno de direito custa barato. O principal custo do curso é o corpo docente. Um professor, um quadro e, no máximo, um projetor de slides compõem a estrutura essencial de um curso de direito. Para que os alunos consigam aprender as matérias do curso, não são necessários laboratórios de ensino com equipamentos sofisticados e caros. Valendo-nos de uma analogia conceitual da teoria econômica, esses insumos se assemelham a uma das características dos bens públicos: a não rivalidade, situação em que o consumo de um bem por uma pessoa (aluno) não reduz a quantidade disponível desse bem para os demais (resto da turma). Por isso, o custo desses insumos é rapidamente dissipado quando dividido por uma quantidade muito grande de pessoas.

Já cursos como medicina, engenharia, biologia, geologia e ciência da computação custam caro. No caso desses cursos estratégicos, tanto o custo marginal quanto o custo médio dos alunos é alto. O custo marginal é alto porque há diversos insumos, necessários para o provimento de um curso de qualidade aceitável, que são rivais, i.e., o uso deles por um aluno compromete a disponibilidade para outro (e.g., computadores e licenças individuais de software para cada aluno em um curso de programação). O custo médio também é alto porque os custos fixos desses cursos (aqueles que correspondem às despesas com insumos não rivais) são significativamente maiores (e.g., laboratórios de ensino e pesquisa). Embora parte desses custos seja arcada pelos alunos, as IES devem, por exigências regulatórias do MEC, disponibilizar um mínimo de infraestrutura instalada, cujo custo é alto. Por isso, a quantidade de vagas oferecida para esses cursos tende a ser baixa, tanto na rede pública quanto na rede privada.

\subsection{MERCADO DE EDUCAÇÃO SUPERIOR: SUBINVESTIMENTO EM ÁREAS ESTRATÉGICAS}

Na prática, é possível concluir que: (i) cursos marcados por altos custos médios e marginais

\footnotetext{
${ }^{26}$ Essa é a conclusão de Trelha et al. (2008), após apurarem os custos de todos os cursos de uma instituição federal e verificarem que medicina, ciências da saúde e geociências são os cursos que custam mais caro, e que letras, direito e ciências sociais são os que custam menos. À conclusão semelhante também chegaram Magalhães et al., ao apurarem o custo médio de formação de alunos de cursos diferentes oferecidos pela Universidade Federal de Viçosa em 2004. Os dados produzidos pelos autores mostram que, enquanto o custo médio de formação de um aluno de graduação cursando engenharia civil e ambiental é de R\$ 42.259,01, o aluno de direito custa apenas R\$ 22.861,37, e o de administração, R\$ 20.146,33 (MAGALHÃES et al., 2010, p. 662-663).

${ }^{27}$ Para uma descrição interessante dos materiais e equipamentos necessários num curso de medicina de universidade particular, vide CHAMMAS, 2014.
} 
por aluno tendem a ofertar menos vagas; e (ii) cursos marcados por baixos custos médios e marginais por aluno tendem a ofertar mais vagas. Por isso, os cursos do tipo (i) têm menos propensão a ociosidades, enquanto cursos do tipo (ii) têm maior propensão a ociosidades. O impacto dessa conclusão para o Prouni é evidente: o Programa depende, como mencionado acima, da alta ociosidade das IES privadas, mas essa ociosidade não se manifesta da mesma forma em todos os cursos por elas ofertados. Isso explica a razão pela qual a oferta de bolsas do Prouni para cursos estratégicos é significativamente menor do que para cursos não estratégicos.

Esse problema de subinvestimento em cursos estratégicos não é característica singular do Prouni, e sim do mercado de educação superior como um todo. Como mostrado na seção I, um dos grandes obstáculos a ser vencido pelo ensino superior brasileiro era (e, em certa medida, continua sendo) expandir o número de vagas e, ao mesmo tempo, reduzir a desigualdade de acesso. Para alcançar esse objetivo, a estratégia escolhida parece ter sido estimular a oferta, sem, no entanto, selecionar alguns cursos que, por serem “estratégicos” para o desenvolvimento econômico, mereceriam estímulo estatal diferenciado e reforçado.

Conceder isenções fiscais e tratar a educação superior como bem privado, sujeito apenas a uma forma mais branda de regulação estatal, certamente contribuiu para um aumento no número de IES privadas nos últimos anos ${ }^{28}$; entre 1980 e 2013 houve um aumento de aproximadamente 306\% no número dessas instituições. Mas a concessão de isenções fiscais e o tratamento da educação superior como bem privado também contribuíram para o subinvestimento justamente na oferta dos cursos hoje considerados mais estratégicos para o desenvolvimento do País. Em 1998, as IES privadas ofertavam apenas 81 cursos da classificação “ciências biológicas” e 136 cursos de “engenharia/tecnologia”; por outro lado, ofertavam 1.485 cursos de “ciências sociais aplicadas” - que inclui direito e administração - e 740 cursos de "ciências humanas"29. Atualmente, a predominância de cursos de ciências sociais aplicadas se mantém. De acordo com o Censo da Educação Superior de 2012, há 9.552 cursos dessa categoria no Brasil, contra 3.767 cursos de engenharia, produção e construção, o que é particularmente significativo, considerando que 71,30\% das IES no Brasil são privadas.

\footnotetext{
${ }^{28}$ De acordo com dados do INEP, havia, em 1980, 682 IES privadas no Brasil. Em 1998, esse número já havia subido para 764. Em 2013, havia um total de 2.090 IES privadas no País. Essas informações constam do portal do INEP, referentes ao Censo de Educação Superior. Cf. <http://goo.gl/SvnyaE>.

${ }^{29}$ Esses números explicam a distribuição de matrículas por IES privadas. De acordo com dados do INEP, referentes a 1998, 79.132 alunos se matricularam em cursos de IES privadas classificados como "engenharia/tecnologia", e apenas 16.196 em cursos classificados como "ciências biológicas"; nesse mesmo ano, 698.677 alunos se matricularam em cursos de IES privadas classificados como "ciências sociais aplicadas", e 168.640 em cursos de "ciências humanas".
}

Revista da Faculdade de Direito - UFPR, Curitiba, vol. 61, n. 3, set./dez. 2016, p. 119 - 139 


\section{CONCLUSÃO}

Os dados acima mostram que o Prouni, tal como está estruturado, não altera o padrão de expansão da distribuição dos cursos oferecidos pelas IES a ele aderentes. Vale ressaltar que esse não é o objetivo declarado do Programa, mas dada a necessidade, reconhecida pelo próprio governo, de aumentar a formação superior em áreas consideradas estratégicas, a questão que se levanta diz respeito às possíveis dificuldades inerentes à implementação de políticas com essa finalidade. Uma possível explicação para isso está na dificuldade atrelada à elaboração e implementação de inovações institucionais que alterem trajetórias ou padrões históricos consolidados. Há toda uma corrente na literatura institucional que se utiliza do conceito de path dependence para analisar a presença de positive feedbacks nos processos de desenvolvimento institucional (vide, e.g., PIERSON, 2004). A ideia é simples, mas tem fortes implicações para a descrição de processos históricos de formulação e implementação de políticas públicas e, consequentemente, para a proposição de alternativas institucionais.

Embora com o objetivo de explicar processos de mudanças tecnológicas, Douglass North (1991, p. 109) adaptou o conceito de path dependence para explicar o desenvolvimento de instituições. De acordo com esse autor, as organizações da sociedade devem sua existência às oportunidades proporcionadas pela matriz institucional vigente. Ou seja, as oportunidades que se apresentam para essas organizações se limitam àquelas que são produzidas por um dado marco institucional. Uma vez que as atividades correntes de uma política pública definem benefícios aos atores nela envolvidos, os custos de alteração do modelo institucional vigente se tornam elevados. Esses custos geralmente se dividem em: (i) elevados custos fixos no investimento de novas instituições, práticas, tecnologias, etc., o que estimula os indivíduos e organizações a permanecerem no status quo; (ii) efeitos de aprendizado - ou seja, há um custo de aprendizado de novas práticas institucionais; (iii) efeitos de coordenação, que se referem aos benefícios crescentes recebidos por indivíduos e organizações em uma atividade, à medida que novos atores adotam a mesma opção institucional; (iv) custos relacionados à incerteza de novos arranjos institucionais, que aumentam à medida que o tempo passa e são diretamente relacionados à complexidade do contexto institucional existente. Nesse sentido, uma determinada configuração institucional tende a levar, em longo prazo, a processos de autorreforço (PIERSON, 2004, p. 35).

A Lei n. 11.096/2005, que instituiu o Prouni, insere-se no modelo institucional histórico de expansão de oferta de cursos de educação superior vigente até hoje no Brasil, sem alterá-lo. Esse modelo de expansão é caracterizado por uma estrutura de incentivos que gera subinvestimentos em cursos de áreas “estratégicas” e um sobreinvestimento em cursos não estratégicos. A razão para isso 
reside nas diferenças entre as estruturas de custos de cursos estratégicos e de cursos não estratégicos. Aqueles, além de estratégicos, custam caro, enquanto estes, embora não estratégicos, custam menos e são marcados por altas ociosidades. Por isso, o Prouni, que depende da ociosidade de vagas de IES privadas, oferta tantas bolsas para cursos não estratégicos e tão poucas para cursos estratégicos.

A conclusão a que chegamos neste trabalho não deve ser, de forma alguma, enxergada como uma crítica ao Prouni. Não estamos dizendo que o Programa é estruturalmente problemático enquanto política pública. Tampouco estamos dizendo aqui que não é importante formar bacharéis em direito ou em administração de empresas. Como política de democratização e expansão de acesso ao ensino superior, o Prouni é exitoso; considerando os dados de acesso ao ensino superior no Brasil referentes ao período anterior à sua implementação, nota-se que era mais do que necessário criar uma política pública reparatória, voltada à correção da desigualdade de acesso. Assim, nossa interpretação dos dados acima é que a oferta de cursos estratégicos precisa ser estimulada, e não que cursos como administração ou direito precisam ser desestimulados. Isso requer, necessariamente, que sejam reconhecidas as especificidades do setor de educação superior, marcado por falhas de mercado decorrentes de um modelo de expansão de oferta mal planejado, que levou a subinvestimentos socialmente indesejáveis e tornou necessárias, portanto, políticas complementares de estímulo a cursos que são estratégicos para o desenvolvimento nacional.

\section{REFERÊNCIAS}

ALMEIDA, S. O avanço da privatização na educação brasileira: o ProUni como uma nova estratégia para a transferência de recursos públicos para o setor privado. 2006. 123 f. Dissertação (Mestrado em Educação) - Faculdade de Educação da Universidade Federal Fluminense, Niterói, 2006.

AMARAL, D. P.; OLIVEIRA, F. O Prouni e a conclusão do ensino superior: questões introdutórias sobre os egressos do programa na zona oeste do Rio de Janeiro. Ensaio: aval. pol. públ. Educ., v. 19, n. 70, jan./mar. 2011a.

O Prouni e a conclusão do ensino superior: novas trajetórias pessoais e profissionais dos egressos. Ensaio: aval. pol. públ. Educ. vol. 19, n. 73, out./dez. 2011 b.

BERTOLIN, J. Os quase-mercados na educação superior: dos improváveis mercados perfeitamente competitivos à imprescindível regulação do Estado. Educação e Pesquisa (USP - Impresso), v. 37, n. 2, mai./ago. 2011.

BIZONI, Alessandra. Ensino superior com sabor jabuticaba. Boletim comunitário da Universidade Candido Mendes, Rio de Janeiro, 19 nov. 2013. Disponível em: <http://goo.gl/bDOQi2>. Acesso em: 27 jul. 2015.

BONFANTI, C.; MARTINS, V. Brasil tem meio milhão de vagas. Saiba onde falta mão de obra. 
Estado de Minas, Belo Horizonte, 11 mar. 2012. Disponível em: <http://goo.gl/g8uLPr>. Acesso em: 14 jun. 2015.

BRASIL. Lei n. 11.096, de 13 de janeiro de 2005. Institui o Programa Universidade para Todos PROUNI, regula a atuação de entidades beneficentes de assistência social no ensino superior; altera a Lei no 10.891, de 9 de julho de 2004, e dá outras providências. Diário Oficial da União, Brasília, DF, 14 jan. 2005. Disponível em: <http://goo.gl/V3Aw1>. Acesso em: 13 ago. 2015.

Lei n. 5.540, de 28 de novembro de 1968. Fixa normas de organização e funcionamento do ensino superior e sua articulação com a escola média, e dá outras providências. Diário Oficial da União, Brasília, DF, 23 nov. 1968, retificado no Diário Oficial da União de 3 dez. 1968. Disponível em: <http://goo.gl/aEgmMD>. Acesso em: 13 ago. 2015.

. Lei n. 10.172, de 9 de janeiro de 2001. Aprova o Plano Nacional de Educação e dá outras providências. Diário Oficial da União, Brasília, DF, 10 jan. 2001. Disponível em: <http://goo.gl/LVa8Jz>. Acesso em: 13 ago. 2015.

. Lei n. 9.870, de 23 de novembro de 1999. Dispõe sobre o valor total das anuidades escolares e dá outras providências. Diário Oficial da União, Brasília, DF, 24 nov. 1999. Disponível em: <http://goo.gl/IPyh42>. Acesso em: 13 ago. 2015.

. Medida Provisória n. 213/2004, de 10 de setembro de 2004. Institui o Programa Universidade para Todos - PROUNI, regula a atuação de entidades beneficentes de assistência social no ensino superior, e dá outras providências (Convertida na Lei $n^{\circ}$ 11.096, de 2005). Diário Oficial da União, Brasília, DF, 13 set. 2004, retificado no Diário Oficial da União de 27 set. 2004. Disponível em: <http://goo.gl/sJvdYY>. Acesso em: 13 ago. 2015.

CARVALHO, C. H. A. de. A política pública para a educação superior no Brasil (1995-2008): ruptura e/ou continuidade? 2011. 457 f. Tese (Doutorado em Ciências Econômicas) - Instituto de Economia da Unicamp, Campinas, 2011.

Reforma Universitária e os Mecanismos de Incentivo à Expansão do Ensino Superior Privado no Brasil (1964-1984). 2002. 191 f. Dissertação (Mestrado em Ciências Econômicas) Instituto de Economia da Unicamp, Campinas, 2002.

; LOPREATO, F. Finanças públicas, renúncia fiscal e o ProUni no governo Lula. Impulso, v. 16, n. 40, 2005.

CATANI, A. M. et al. Prouni: democratização do acesso às instituições de ensino superior? Educar em Revista, v. 29, 2006, p. 127.

CHAMMAS, P. Concluir custa caro: formar em Medicina pode custar até R\$ 424 mil. Correio24Horas, Salvador, 14 mar. 2014. Disponível em: <http://goo.gl/lvs4mI>. Acesso em: 14 jun. 2015.

COLLUCCI, C. Onde falta médico, faltam dentistas e enfermeiros, mostra pesquisa. Folha de São Paulo, São Paulo, 1 set. 2013. Disponível em: <http://goo.gl/ybbS9J>. Acesso em: 14 jun. 2015.

CUNHA, L. C. V. et al. Políticas públicas de incentivo à educação superior brasileira: acesso, 
expansão e equidade. Revista de Iniciação Científica, Tecnológica e Artística, v. 4, n. 4, 2014.

HADDAD, F.; BACHUR, J. P. Um passo atrás, dois à frente. Folha de São Paulo, Opinião, São Paulo, 11 dez. 2004. Disponível em: <http://goo.gl/F9Zuhl>. Acesso em: 14 jun. 2015.

INSTITUTO BRASILEIRO DE GEOGRAFIA E ESTATÍSTICA (IBGE). Pesquisa nacional por amostra de domicílios 2001. Rio de Janeiro: IBGE, 2003.

. Síntese de Indicadores Sociais: Uma Análise das Condições de Vida da População Brasileira. Rio de Janeiro: IBGE, 2009. Disponível em: <http://goo.gl/szv5UJ>. Acesso: em 29 jul. 2015.

LINS, L. M. et al. Escassez de engenheiros no Brasil? Uma proposta para sistematização do debate. Novos Estudos (Cebrap), n. 98, mar. 2014.

MAGALHÃES, E. A. et al. Custo do ensino de graduação em instituições federais de ensino superior: o caso da Universidade Federal de Viçosa. Revista de Administração Pública, v. 44, p. 637-666, 2010.

MANCEBO, D. “Universidade para todos”: a privatização em questão. Pro-Posições, v. 15, n. 3 (45), 2004.

LORENZONI, Ionice. Bolsistas revelam em pesquisa as vantagens da graduação. MEC Notícias, Educação superior, 06 maio 2009. Disponível em: <http://goo.gl/hBP1y1>. Acesso em: 14 jun. 2015.

NEVES, C. E. B. et al. Acesso, expansão e equidade na educação superior: novos desafios para a política educacional brasileira. Sociologias, ano 9, n. 17, jan./jun. 2007.

NORTH, D. Institutions. The Journal of Economic Perspectives, v. 5, n. 1, inv. 1991.

PACHECO, E.; RISTOFF, D. Educação superior: democratizando o acesso. Brasília: Inep, 2004.

PIERSON, P. Politics in Time: History, Institutions, and Social Analysis. New Jersey: Princeton University Press, 2004.

QUEIROZ, F. C. B. P. et al. Transformações no ensino superior brasileiro: análise das Instituições Privadas de Ensino Superior no compasso com as políticas de Estado. Ensaio: aval. pol. Públ. Educ., v. 21, n. 79, abr./jun. 2013.

SAMPAIO, H. Ensino superior no Brasil: o setor privado. São Paulo: Hucitec/Fapes, 2000.

SOUZA, M. Os empresários e a educação. Petrópolis: Vozes, 1981.

TEIXEIRA JR., S. “Não existe risco jurídico no Brasil”, diz Dilma. Exame.com, 25 set. 2013. Disponível em: <http://goo.gl/WbkN9i>. Acesso em: 14 jun. 2015.

TRELHA, C. S. et al. Cursos de medicina com currículos inovadores são mais caros? Análise de custos do curso integrado de graduação de medicina da Universidade Estadual de Londrina. Revista Brasileira de Educação Médica, v. 32, p. 160-173, 2008. 


\title{
COURSES OFFERED BY PROUNI AND THE JOB MARKET
}

\begin{abstract}
In this article we examine the current breakdown of Prouni scholarships per kind of undergraduate course so as to identify the main fields of knowledge that are made available in the higher education market by Prouni and to which extent the program is compatible with the need to foster higher education in strategic fields of knowledge, which is an official priority of the government that designed the program. We argue that path dependence can contribute to explaining why Law No. 11.096/2005, which instituted Prouni, falls within the institutional framework that comprises the growth of higher education supply still existent today in Brazil. This model is focused on private institutions of higher education and is characterized by an underinvestment in fields of knowledge that are strategic for national development.
\end{abstract}

\section{KEYWORDS}

Public policies. Prouni. Higher education. Path dependence. Strategic courses.

Recebido: 1 de fevereiro de 2016

Aprovado: 15 de março de 2016 